\title{
Implementing RFID in Production Systems: A Case Study from a Confectionery Manufacturer
}

\author{
Chris Kürschner \\ Universität St. Gallen, Germay \\ c.kuerschner@sap.com \\ Alexandra Brintrup \\ University of Oxford \\ alexandra.brintrup@sbs.ox.ac.uk \\ Paul Bowman \\ BT, UK \\ paul.bowman@bt.com \\ Erica Dubach \\ ETH Zurich \\ edubach@ethz.ch \\ Frédéric Thiesse \\ University of Wuerzburg \\ frederic.thiesse@uni-wuerzburg.de
}

\begin{abstract}
This paper presents a case study on the research and development of an RFID-based work-inprogress container tracking system at a confectionery manufacturer. We report on the management of the RFID project, the system design and the economic evaluation of the solution as compared to the situation before implementing RFID. We discuss the case from a practitioner's view as well as from an academic view regarding the theoretical implications that can be drawn from it. The lessons learned from the project can help other companies to better anticipate the challenges they may experience and make them aware of the possible ways to cope with such challenges prior to starting an RFID implementation.
\end{abstract}

Keywords: RFID, Case study, Container tracking, Production, Work-in-progress, IT adoption, IT value. 


\section{Introduction}

Radio Frequency Identification (RFID) is a family of contactless object identification tag technologies that offer automated data acquisition and processing about arbitrary physical objects. Three main types of RFID exist: Passive RFID, where the tags are activated by radio waves emitted from an RFID reader enabling the transfer of a unique identification; active RFID tags that have the ability to transfer identification and other associated data and semi-passive RFID tags which use battery power to increase the range of tags. The main difference between RFID and other auto-id technologies particularly the classical bar code - is in the complete automation of the identification procedure, which allows organisations to capture data on physical processes even in environments that were previously impractical to operate RFID in. Thus, RFID not only streamlines manual object identification processes but also paves the way to many interesting applications, including distributed manufacturing, better retail services, automated maintenance and recycling. As a consequence, RFID is currently the subject of much interest among manufacturing companies. Gunasekaran and Ngai (2007) expect that new technological platforms, partly based on RFID, will help manufacturing companies in knowledge diffusion and transfer in the 21st century, in various areas from production planning and logistics, to the gathering of customer service requirements once products are in use. Jun et al. (2007) argue that the end of life recovery of products and their integration into the manufacturing phase present another potential area to be supported by RFID.

While several manufacturers are adopting RFID by force of mandates in the supply chain, many are also seeking ways to use the technology to improve their internal production processes. The impact of RFID applications on operational performance has been discussed in a large body of academic and non-academic literature (e.g., Bapat and
Tinnell, 2004; BearingPoint, 2005; McBeath, 2006). Although these sources might serve as a valuable foundation for understanding the industry's interest in RFID, the broad majority of such publications suffers from what Dutta et al. (2007) call a "credibility gap", i.e., these are mainly journalistic and promotional in nature. In contrast, there is a lack of academic studies that reveal critical success factors and offer lessons learned from real-world projects (Lee and Özer 2007). For companies to be able to assess the actual impact of RFID technology on existing production processes, an in-depth understanding of the design, development and implementation of such systems in the field is necessary.

Against this background, it is the goal of this paper to fill this gap by investigating the course of one specific RFID project in detail. In contrast to the majority of prior works on RFID, we do not set the research focus on an application in retail, healthcare, or the coordination of different partners in a supply chain, but rather on the use of the technology for company-internal purposes in a large confectionery manufacturing domain. In the case studied, the potential of RFID to provide accurate and complete batch level information in a timely manner was examined within a production process from raw materials to finished products. The main objective of the project was to enhance existing processes through improved RFIDenabled track and trace of containers which carry work-in-progress products. The company aimed to reduce process waste generated due to traceability issues.

On the one hand, we aim to utilise the case study to extract the key lessons learned from a practitioner's point of view, which may be helpful for other companies planning to implement RFID within a manufacturing plant. On the other hand, we intend to complement prior academic studies on RFID by considering the implications of this novel application from a theoretical perspective. Since the nature of our research can be described as explorative, we chose the case 
study method as a qualitative research approach (Eisenhardt, 1989; Yin, 2003; Paré, 2004). This method allows the researcher to investigate a contemporary phenomenon in its real-world context and provides a way of collecting, organising and analysing data to obtain comprehensive, systematic and indepth information about the case. Case study research is especially useful for early, exploratory investigations where the phenomenon is not yet completely understood and for which existing theory seems insufficient (Benbasat et al., 1987; Meredith, 1998). Because of the early stage of RFID adoption and the small number of systems in actual use which can be regarded as representative, we employed a "critical case sampling" strategy (Patton, 2002). Accordingly, we were looking for a case that is information-rich and permits generalisation and maximum application to other cases. The project under consideration seems well-suited to meeting these requirements due to the level of detail of the available information and the focus on Work-In-Progress (WIP) tracking, which poses an application that is relevant to several other manufacturing systems.

Our research objective provides a clear focus for the study and permits us to specify the kind of data to be gathered. As is typical in case studies, data were collected using a mixture of techniques (Yin, 2003). The data from this research resulted from actively taking part in the different phases of the project. Data collection throughout the project was based on

- $\quad$ participant observation (e.g., workshops of the project team)

- interviews (e.g., semi-structured telephone interviews),

- company-internal data (e.g., documentation of manufacturing processes),

- $\quad$ supplier-provided data (e.g., proposals and offers of RFID suppliers) and

- $\quad$ physical observations (e.g., factory site visits).
The remainder of this paper is structured as follows: first, we present a short review of previous case studies on RFID applications in the manufacturing domain. This is followed by a detailed description of the investigated application, throughout which we critically evaluate the findings of the case. The discussion section considers the case from a practical and a theoretical perspective. The paper closes with a summary, conclusions and an outlook on further research.

\section{Literature review}

Automated data collection technologies have become omnipresent in today's production and logistics operations. It was particularly the introduction of the bar code that laid the foundation for substantial improvements in performance and process quality in manufacturing companies (Lindau and Lumsden, 1999). The rise of RFID in recent years and its unique characteristics in comparison to prevalent technologies have sparked an intensive debate in academia and practice on the benefits to be expected. Some of the characteristics that make RFID a frontrunner are its robustness in harsh industrial environments and its ability to provide bulk identification without the need for line of sight.

The vast majority of academic works on RFID in the Information System (IS) and operations management literature has focused on its application in the supply chain, particularly in the context of the retail industry. Often-cited examples are the works by Kärkkäinen and Holmström (2002), McFarlane and Sheffi (2003), Jones et al. (2004), Srivastava (2004), Angeles (2005) and Bose \& Pal (2005). Virtually the same holds for analytical research using mathematical models and simulations, which aims to quantify the impact of RFID information on operational performance. An issue that received particular interest on the part of Operations Management researchers is the phenomenon of inaccuracies in retail inventories. Examples of this research stream include the works by Kang and Gershwin (2005) Gaukler et al. (2007), Heese (2007), Rekik et al. (2008) and 
Rekik et al. (2009). In contrast to that, we are aware of only two analytical studies on the use of RFID in production systems, namely the works by Gaukler and Hausman (2008) and Hozak and Collier (2008). Regarding empirical publications, there are only a few studies of RFID projects in the manufacturing domain that reveal critical success factors and discuss lessons learned from real-world projects (Ngai et al., 2008). In the following, we present a brief review of these prior academic works.

Strohbach et al. (2004) studied a prototype for handling and storage of chemicals in the specific context of a BP chemical plant in Hull, UK. Correct handling of chemicals is critical to ensure protection of the environment and safety in the workplace. Although manual processes are clearly defined, they are not always foolproof and may lead to accidents or even to hazardous situations. The described system takes a step beyond existing RFID applications by shifting business logic from resource-intensive backend systems to systems embedded in the object itself. Using sensors, wireless communication and computing components, chemical drums themselves will warn operators when the storage limit in a warehouse is reached, if a leak occurs or if a drum is placed in the wrong location. In contrast to traditional architectures, sensor data is not collected in a central database from where decisions are made. Instead, data is stored and the business logic is performed locally.

Thiesse et al. (2005) and Thiesse and Fleisch (2008) report on the design and implementation of a real-time identification and localisation system that Infineon Technologies uses in its wafer fabrication facility in Villach, Austria. Like other companies in the industry, the company seeks to increase automation in its production logistics to reduce stock and improve efficiency. Therefore, the company decided to start the LotTrack project to make a product's entire production process transparent and thus controllable. The project aimed at decreasing lead times, eliminating handling errors and reducing non-value-added activities. The implemented system combines active and passive RFID as well as ultrasonic sensors to track wafer boxes and wafer cassettes in the company's chipmanufacturing process.

Günther et al. (2008) present the findings of six case studies on the use of RFID within manufacturing processes. However, only one case describes a real-world application, while the other five cases simply analyse existing production processes and the potential use of RFID technology. The one real-world case examines the RFID implementation of a firsttier automotive supplier of engine cooling modules. The manufacturer uses RFID technology at two assembly lines for tracking cooling modules during the production process. The company introduced RFID at the request of a customer who expected improved traceability of its products. Traceability is of high importance, particularly for original equipment manufacturers, partly because of legal requirements and partly to improve quality by identifying faulty components quickly and reliably.

Beyond the scarce academic discussion of RFID applications in production systems, a number of additional cases are known from the trade press, which illustrate the potential that the technology may offer in industrial settings. Nevertheless, these case descriptions do not provide a complete overview of the how and why of RFID implementation:

Lawsgroup, a Chinese contract manufacturer that produces garments for U.S. retailers uses RFID technology to automate the tracking of work-in-process items such as raw materials, semi-finished components and finished garments. The system provides visibility into the company's operations and enables the company to produce more garments and react more quickly to changes than before. Prior to its decision for deploying an RFID system, Lawsgroup experienced growing pressure from its customers to manufacture higher numbers of variations in shorter lead times. After implementation of an RFID system, the back-end system is able to 
track how many pieces are completed and which pieces of an order have reached a certain working station. The system resulted in improvements including easier performance measurement and better production decision making as well as shorter lead times and higher production-planning accuracy (O'Connor, 2006a).

- Blommer Chocolate, a cocoa-processing company, implemented an RFID tracking system to improve inventory control and visibility. The project was initiated after the acceptance of the Bioterrorism Act, which requires food suppliers to track the custody and quality of raw materials and finished products in real-time. The Bioterrorism Act mandates tracking raw materials as they arrive at the manufacturing plants, ensuring that samples of each shipment are tested. In addition, it is necessary to track ingredients going into finished goods and shipments are leaving the plant. Furthermore, the company aimed at making its warehouse operations more accurate and efficient. As a side-effect, the company could speed up its loading process and can now follow the first-expirefirst-out (FEFO) model for ingredients, which means that the oldest ingredients are used first (O'Connor, 2006b).

- DaimlerChrysler, a global vehicle manufacturer, piloted an RFID project to increase the visibility of parts in their production sites. In a proof-of-concept exercise the company added passive tags to existing Kanban parts-management cards. The goal of the project was to improve the flow of parts from the on-site storage spaces to workstations at the production line. Using RFID, the company is able to track whether parts are in storage or being used on a production line. Although the increased visibility eliminates the need for labourintense and time-consuming annual stock counts (see section), the key driver is the enablement of electronic Kanban by providing an accurate inventory the manufacturer will be able to automate part orders, requests and inquiries from the suppliers (Collins, 2006).

- In 2004 Gardeur AG, a German clothing manufacturer, decided to deploy a RFID system to track garments from production to its warehouse using reusable tags. At that time, the company did not know how many products arrived at their warehouses and distribution centres, nor was Gardeur able to confirm that all goods from a production site actually arrived at their planned destinations. Moreover, when a delivery arrived, employees had to spend a lot of time counting and sorting the different product variants. Thus, the goal of the implementation was to reduce manual work, to reduce shrinkage and to increase the efficiency of the underlying processes. In this application, individual items are tagged when they are shipped and read when they arrive at the warehouse. Upon arrival of the goods, their tags are removed and reused in a subsequent delivery (Wessel, 2006).

The research presented in this study goes beyond the literature in two respects. First, we present a case study of an RFID system for WIP tracking, an application scenario that has often been mentioned in overview papers on RFID benefits. However, we are not aware of any prior work that investigates the actual process of designing a corresponding system in more detail. Second, we do not limit ourselves to the conceptual foundations of WIP tracking and the value of RFID thereof. In contrast to other works that concentrate more on the quantification of operational benefits of RFID with the help of mathematical models, we seek to shed light on the manyfold issues that arise in the management of real-world implementation projects through a case study based methodology.

\section{Case description}

This section presents the case under consideration in chronological order, following the methodology proposed by Dyer and Wilkins (1991). After introductory background information on the manufacturer and its business, we describe the main phases of the RFID implementation: preliminary analysis, detailed process analysis, proposed solution architecture, cost and benefits analysis, selection of partners, formation of the project 
team and strategies on human factors. Throughout the case description we extract lessons learned regarding implementation in the manufacturing domain.

\section{Background}

The company under consideration is a major international confectionery manufacturer and operates in the Fast-moving Consumer Goods (FMCG) sector. The company employs Manufacturing Resource Planning (MRP) philosophy for its production processes. In 2005 the company initiated a project with the aim to standardise the business processes and procedures used within its many factories. A mandatory requirement was the implementation of batch management functionality for ingredients, packing as well as semi-finished and finished materials in the company's Enterprise Resource Planning (ERP) system. The product that we consider in this case study is packaged, mixed sweets with seasonal demand. The batch is the principal means of tracing and controlling stock by breaking down the stock of materials into manageable amounts. For example, for a semi-finished material, a batch may be equal to a production period of one hour. A bar code solution was implemented to record all movements of semi-finished sweets within the factory, thereby reducing the administrative overhead in terms of data collection to a minimum. Each batch of products is transported within the factory with a reusable Intermediate Bulk Container (IBC). The IBC is a large steel-framed plastic container, which is moved by forklift trucks to different locations within the factory. When products are moved, bar codes on these containers are manually scanned and manually linked with bar codes at various process locations.

After two years of bar code implementation, the company concluded that while the bar code-based system has proved to be of significant benefit, a number of issues have been identified with its use which might be overcome by the implementation of RFID technology:
Firstly, all material movements must be recorded in order for batch management functionality to be of benefit. Obviously, this data is only available if operators carry out scan transactions in a timely and reliable manner upon each stock movement. However, for many reasons, accurate data is not available. For instance, operators are working under time pressure and do not always perform the scanning procedures correctly. This is especially the case during peak season when temporary operators are employed who have less experience and skill. Secondly, at some locations it is not possible to obtain a direct line of sight to the bar code label. This is particularly an issue when moving more than one stock unit at a time or when carrying out inventory counts of stock in high-racking storage locations. Stock in these locations is ignored, giving rise to an inaccurate picture of WIP inventory.

Thirdly, human error during bar code scanning was reported to be an important issue because missing or wrong scan transactions results in a loss of traceability, which means that products may have to be scrapped (i.e., disposed of).

Fourthly, some transactions require operators to verify that the stock is available and is in the right quality state before it is used. In this instance the scanning operation must be carried out in advance of the operation. This has proved to be difficult to enforce. Failure to do so results in incorrect stock being used, potentially leading to stock with inadequate quality leaving the factory and requiring a costly recall.

In addition to the batch management problems listed above, issues relating to the management of the IBCs have been encountered that would also benefit from the introduction of RFID. These include missing history information on assets which leads to maintenance problems and loss of time due to unscheduled maintenance. Furthermore, IBCs are regularly lost due to unauthorised or unplanned movements, resulting in operators having to spend time locating assets and possibly reducing availability of assets at the production lines, potentially resulting in a halt of the production lines. As a result of these 
observations, the company under study examined RFID as a vehicle to remedy the above mentioned issues and to enhance reusable asset visibility, reduce waste and improve operations.

\section{Multi-perspective analysis for viability of RFID}

Initially, a preliminary analysis was conducted to investigate the viability of RFID implementation in the sweets production process. This analysis consisted of the following aspects of implementation (following the framework proposed by McFarlane, 2009):

- Operational reliability, which examined the availability of power and network infrastructure, the scaling capability of the information system architecture and system integration effort

- Technical feasibility, which examined possible tag placement locations on the containers, effects of product content on performance, the difficulties associated with installing read points and feasibility of identifying fast moving items RFID read points

- Economical viability, which examined cost of hardware, software, project management and integration as well as quantitative and qualitative benefits

- Organisational compatibility, which examined previous experience of the factory personnel in introducing new technology, alignment of the project with existing business improvement efforts, existence of management support and enthusiasm for the project

To carry out an analysis on the above aspects, company representatives were gathered for a brainstorming session, which helped identify questions specific to the pilot under these headings. The team then went on to interview company personnel to answer these questions. For instance, among technical concerns were: interference, speed through readers and the metal content of sweet wraps. For operational feasibility the team needed to know if the current process was well defined, whether the information system was scalable and whether electrical installation was possible at the requested read points. For economical viability the team considered whether traceability was critical, whether the item was of high value, whether stock buffers were high, whether throughput could be improved and waste could be reduced. For organisational capability the team examined whether the RFID project was aligned with existing business strategy and whether the organisation was used to developing non-standard operating procedures. To conduct the analysis, the company needed information from key contacts across a variety of departments, such as finance, operations, Human Resources and Information Technology. The project team sought help from factory management to bring the relevant people together. The above analysis ensured that the operational environment was sustainable for RFID, the project was technically possible, it had economic sense and that the organisation had the skills to carry out the project. At later stages of the project the team increasingly became aware of the value provided by this initial stage. Covering these aspects at an early stage helped the company understand whether the project was possible at all and pinpoint the weakest areas for improvement. In addition it was easier to request help of personnel later on since they were involved in the shaping of the project from the very start.

\section{Detailed process analysis}

To examine the process in detail, the as-is manufacturing process, issues and the envisaged future process were analysed. Although the team started with a simple overview diagram it quickly became apparent the data gathered through this diagram were not enough to develop a complete understanding of the process for RFID implementation. Consequently, a Value Stream Analysis was conducted. The value stream displayed process steps and showed whether the process step was purely for operational purposes or added value to the product. It helped identify scan operations and examined how their elimination would 
impact the process. Then Unified Modelling Language (UML) diagrams were drawn to show the information flow in the process, conducted by various actors, such as the operator or components of the business information system. This meant that the physical process and its information flow could be linked. Visualisation allowed for the identification of the RFID potential within these processes in terms of process automation, data collection and increased visibility. To develop a complete understanding of the process, close cooperation with the factory personnel was required at this stage. Understanding the process steps in detail was key, in order to develop a feasible, practical, and solution.

In the following, we present a short overview of the process analysis by describing the bar code enabled sweets production process and process issues in detail, before presenting the RFID based solution architecture, associated business case and the proposed project management structure.

The process starts with unwrapped sweets (cf. Figure 1). After the sweets are moulded on the production line, they are individually wrapped and dropped into an empty IBC from an overhead conveyor belt. The IBC has a bar code indicating its contents. When the container is full, an overhead sensor indicates to the operator that the batch is formed and is ready to be taken away. The full container is picked up with a forklift truck and brought to the weighing station at the bottom of a hoist. There, its contents and weight are recorded. This is done by scanning the IBC bar code and a bar code plate on the wall which indicates the line the products came from. This ensures the linkage between WIP stock and current process step. In the back-end system a 'goods receipt' transaction from the wrapping machine is performed and stock from the process order which is running on the line is created. Depending on the current stock buffer at the packing lines, the system indicates that the stock should either be brought directly to the buffer in the packing area or to the cold store for intermediate storage. When the container arrives at the cold store it is placed in a storage pod and scanned to indicate it has arrived at that location. Additionally, in the cold store, information is displayed on a display screen that shows the buffer display that indicates to the operator which container should be sent to the packing area next.

In the above process, before the products reach the packing area, two common errors occur. Firstly, a container is filled but the goods receipt transaction is not carried out at the weigh-scales. When the container is scanned at a subsequent production step, the production operator receives an error message stating that the container is empty. The consequence is that traceability has been lost because it is not possible to discover when and by what process order the container was filled. In this situation of lost traceability, the contents have to be scrapped as waste. Secondly, a container is filled but the goods receipt transaction is carried out incorrectly at the weigh-scales by scanning a bar code representing a production line other than the one that the container was filled on. The implications of this can be far reaching. For example, stock of the wrong sweet type may be created in the back-end system causing an inaccurate stock picture and possibly resulting in a product not being available to be packed when required. Additionally, incorrect costs and material usage might be calculated causing financial inaccuracies and wrong replenishment material might be ordered from suppliers. It may also be impossible to determine when the container was filled and by what process order, resulting in loss of traceability and the container's contents being scrapped as waste.

After WIP material arrives at buffers in the packing area, a location bar code plate on the forklift truck and the container bar code are scanned to assign the IBC its new location. When a full container is needed at a particular tipping line for filling tins or boxes, an operator collects a full container from a buffer area and moves it to the packing line by means of a forklift truck. The empty container is taken off the line and the operator scans the container bar code and a 
status bar code plate. This sets its status to 'empty'. At this point, the system decides where the batch should be sent. Before the IBC carrying the batch is put into the hoist for transfer, a bar code plate at the hoist and the IBC bar code are scanned to set its status to 'in transfer'. Then the full container that is waiting to be tipped over the packing line and a location bar code plate are scanned to associate the container with the tipping line number. The filled tins and boxes are stacked on a pallet. The finished pallet of packaged sweets is scanned and processed in the pallet management system, leading to the end product, ready to be sent to clients.

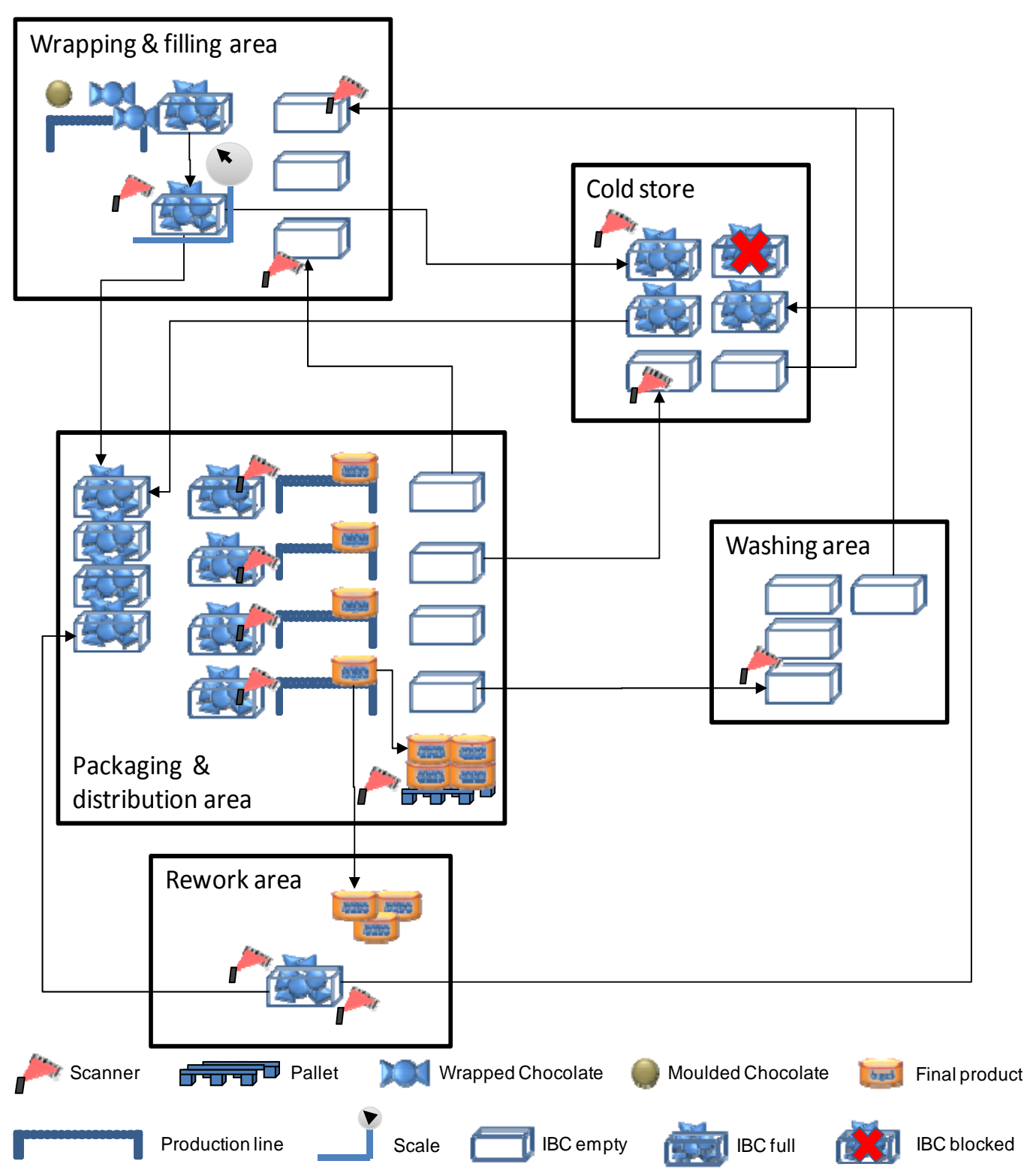

\section{Figure 1. Process overview}

At the packing area two problems regularly goods issue transaction. The implications of occur. Firstly, a container is put onto a tipping point but the operator does not perform the 
incorrect as a container that has been 'used' is still shown as 'in stock'. This can result in errors in production planning and stock not being physically available for packing when it is needed, which can eventually cause the packing lines to stop. Additionally, incorrect costs and material usage might be assigned to the process orders. This can lead to compromised batch traceability. The second regularly occurring problem is that a container is put onto a tipping point and the scan transaction is carried out but the operator does not check the feedback on the scanner. At this point validation must be performed by the backend system as part of this transaction to check that the contents of the container have the correct quality state and that the material in the container is defined on the bill of materials of the packing process order. Ignoring or not observing the feedback may lead to quality issues on the packing order and it could be necessary to scrap or recall the final product.

In the above described process, human error during bar code scanning is reported to be the biggest source of wasted material and time. The current procedures are reliant on production operators performing transactions and checking feedback in a timely and accurate manner. Frequently transactions are carried out incorrectly. Errors in 2006 alone resulted in around 250 containers out of 1104 , each containing around $500 \mathrm{~kg}$ of WIP material, being scrapped, which represents a significant financial loss. Table 1 exemplifies issues relating to human error in the two main parts of the process and waste implication using the lean analogy by Ohno (1998).

\begin{tabular}{|c|c|c|}
\hline Process step & Issue & Description \\
\hline \multirow{3}{*}{$\begin{array}{l}\text { Batch created at the } \\
\text { weighing station }\end{array}$} & Scan errors & $\begin{array}{l}\text { - Scanning a bar code representing a production line } \\
\text { other than that the container was filled on } \\
\text { - Not scanning bar code of container }\end{array}$ \\
\hline & Consequences & $\begin{array}{l}\text { - Traceability is lost -scrap the container contents } \\
\text { - Error message stating that the container is empty. } \\
\text { - Stoed to go back to the line and re-scan. } \\
\text { - system, causing an inaccurate stock picture. } \\
\text { - Incorrect costs and material usage information causing } \\
\text { financial inaccuracies. } \\
\text { Wrong replenishment material may be ordered from } \\
\text { suppliers. }\end{array}$ \\
\hline & $\begin{array}{l}\text { Waste } \\
\text { implication }\end{array}$ & $\begin{array}{ll} & \text { Defects and scrap } \\
\text { - } & \text { Overproduction } \\
\text { - } & \text { Unnecessary motion } \\
\end{array}$ \\
\hline \multirow{3}{*}{$\begin{array}{l}\text { Container arrives at } \\
\text { the packing area }\end{array}$} & Scan errors & $\begin{array}{l}\text { - Container is put onto a tipping point but the operator } \\
\text { does not perform the goods issue transaction through } \\
\text { a bar code scan } \\
\text { - Operator does not check the feedback on the scanner } \\
\text { indicating quality status }\end{array}$ \\
\hline & Consequences & $\begin{array}{ll}\text { - } & \text { Batch traceability compromised - scrap } \\
\text { - } & \text { Line stoppage as unknown sweet pack created } \\
\text { - } & \text { Quality compromise - scrap }\end{array}$ \\
\hline & $\begin{array}{l}\text { Waste } \\
\text { implication }\end{array}$ & $\begin{array}{ll}\text { - } & \text { Defects and scrap } \\
\text { - } & \text { Unnecessary motion } \\
\text { - } & \text { Transport } \\
\text { - } & \text { Waiting } \\
\end{array}$ \\
\hline
\end{tabular}


Using the above analysis, operational reliability, technical feasibility, economical viability and organisational compatibility were investigated in more detail. Once process mapping was completed, a set of requirements emerged which could be used to develop an initial design of the solution in terms of hardware, software and infrastructure. First, an automated scan solution was seen as necessary to eliminate process waste and improve reusable asset management. The solution was supposed to be flexible and easy to integrate with the current system. Second, the solution should be cost effective as there were various process locations.

\section{Solution architecture}

For the design and deployment of the RFID solution a leading pan-European company in the value-added solutions and services industry for automatic identification of goods and people was selected. The company recognised that an easy to integrate, flexible and scalable RFID solution design was important so that the solution could be extended to other processes in an easy and rapid manner. Such a solution aimed at delivering the traceability improvements at low risk and with a quick payback.

Figure 2 depicts the general architecture of the solution. The existing system consisted of the following components: ERP system (SAP), Manufacturing Execution System (MES), Supervisory Control and Data Acquisition (SCADA), weighing scales, bar code scanners, label printers and a wireless network infrastructure. Only the MES needed to be modified for integration. At the heart of the design is the Tag Acquisition Processor (TAP). This component assigns and operates antennas independent of which reader they are connected to. A wide range of readers and antennas from different manufacturers can be mixed, matched and managed to suit the RFID application. Because of its flexibility, the TAP was particularly well suited for an RFID pilot, multi-application and multi-site rollout. Additionally, the TAP supports both standard and application-specific interfaces. It is easily interfaced to MES and other enterprise systems, which was important to the company since this flexible interface approach facilitates rollout across a wide range of the firm's business systems and applications.

During the initial survey and requirements capture, fixed RFID readers were considered for the areas where the three key functions are carried out: filling, weighing and tipping. However, given that there are 70 tipping points that would each need to be capable of identifying an associated container, the installation would have become both costly in terms of equipment and installation as well as complex to set up for reliable operation due to the high density of RFID readers and number of antennas. In this area, tagging the fixed locations of the tipping points and using mobile readers on the forklift trucks was a clearly more economical option as there were only three forklift trucks out of a total fleet on site of more than fifty that had forks modified with a wider pitch capable of fitting around the filling points. The solution was designed with the mounting of the RFID readers and antennas on the forklift trucks (cf. Figure 3) together with a compact truck terminal for the user interface. This mobile design is not intrusive and therefore would not impact the day-to-day running of the operations, which is particularly important during periods of peak activity when errors are most likely to occur and operational environment must be smooth. The alternative would have been to install fixed readers and antennas at the filling, weighing and tipping stations. However, the implementation of a large amount of fixed readers and antennas together with the associated data and power cabling would have resulted in disruptions to the operation. Moreover, this solution would have been more expensive and less flexible.

Since each container could be loaded on the forklift trucks from different sides each has three RFID labels with an identical serial number attached to it. Rigid RFID tags were embedded in the floor just in front of each filling station, to record when an empty container is put onto and removed from a filling point without any manual intervention. 
Pacific Asia Journal of the Association for Information Systems, Vol. 2, Iss. 2 [2010], Art. 4

Implementing RFID in Production Systems: A case Study from a Confectionery Manufacturer/ Kürschner et al

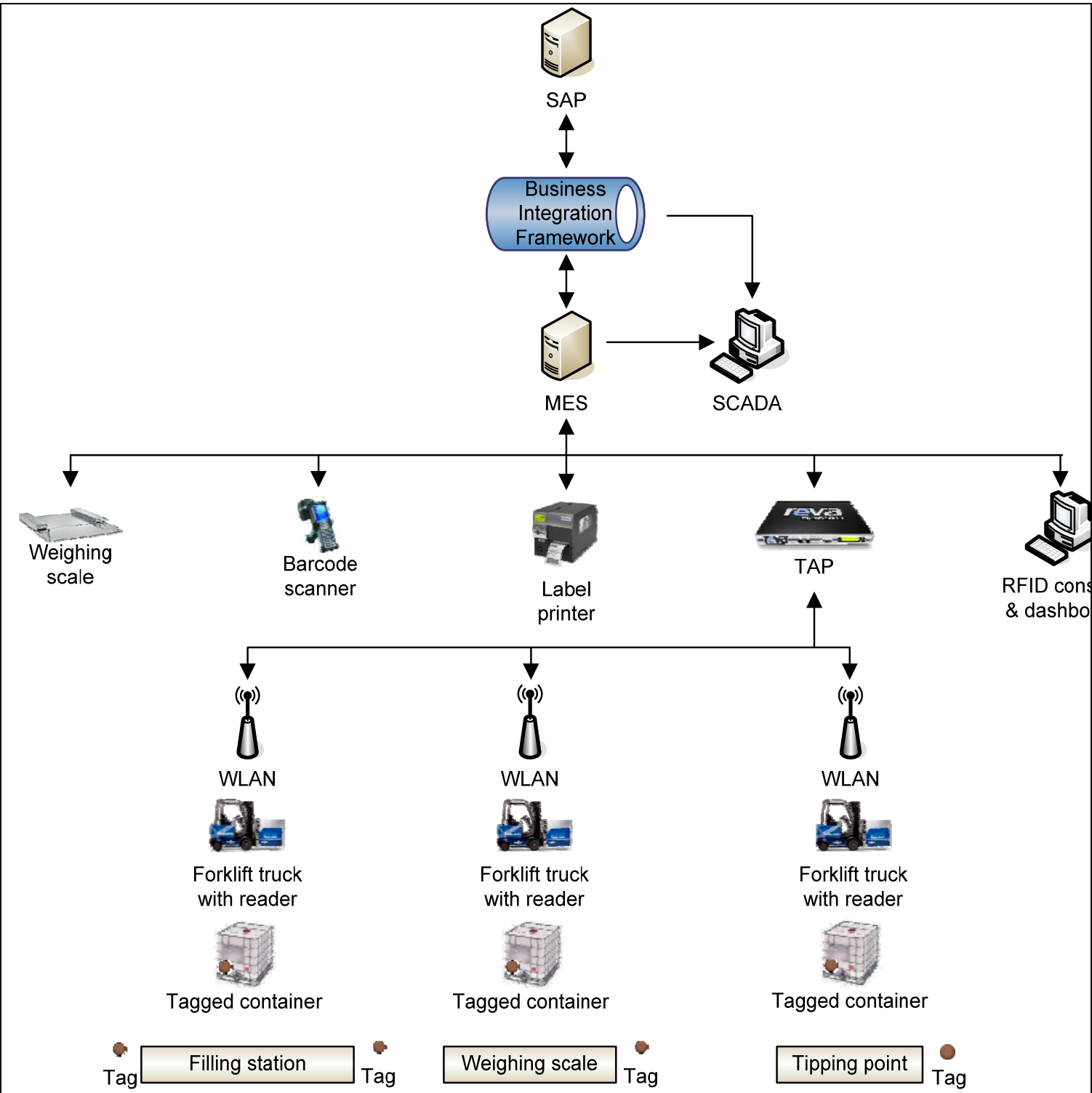

\section{Figure 2 - Architecture for the mobile solution}

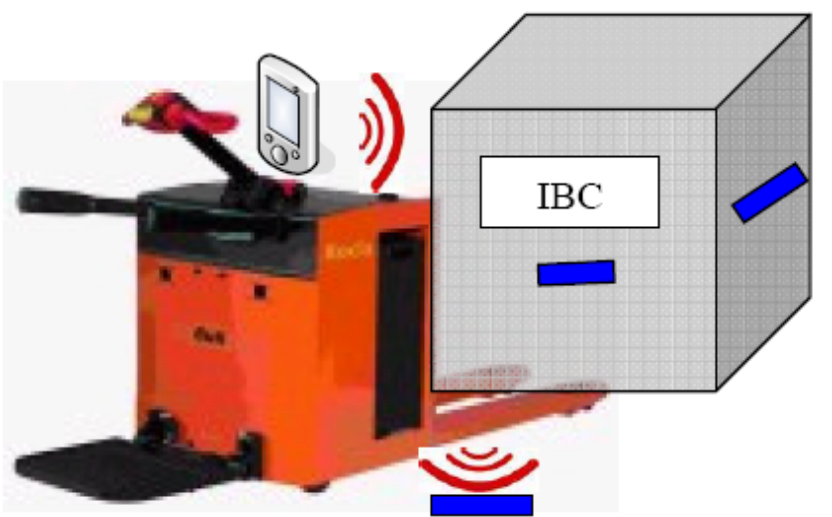

Figure 3 - Forklift reader setup

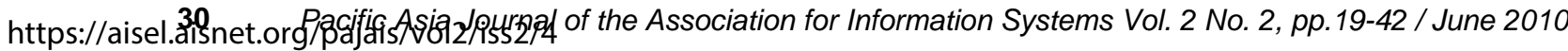


In the filling area, it was anticipated that each of the nine filling points would require modification to accommodate two antennas. Although this was considered to be technically feasible it was likely that any installation, carried out to food hygiene standards, would have been both disruptive and require extensive testing as the filling points are built from steel components, the available space is restricted and the filling points are close to each other. Fitting mobile readers to the forklift trucks was ruled out on the grounds that any of the remaining standard trucks (i.e., those not equipped with an RFID reader) that would be available throughout the factory site could potentially be used in the area. This would increase the risk of containers being moved without the required RFID tags being read. Following further discussions with the local management team and explanation of the technical challenges and options, it was agreed that a simple process could be put in place to reliably ensure that only RFIDenabled forklift trucks would be used in the filling area. Although the initial set up that was envisaged was a conventional one with static reader set up, the end solution was not offthe-shelf, yet more cost effective in the long run.

\section{RFID-enabled process}

By implementing RFID technology on the production lines it is possible to record when and where a batch is placed at or removed from a process step without any manual intervention. With RFID, process data is sent to the backend system where checks are made to ensure that the correct batch is assigned to the correct process. A message showing the result of this validation is returned to the operator and displayed on the forklift terminal screen. For example at the weighing stations, the RFID reader on the forklift truck will detect when a specific container is positioned at a weighing station. Then the container's unique identification number and weight are sent to the back end system, causing the destination location for the full container and again to be displayed to the operator on the forklift terminal. Similarly, automated checks are made to connect the batch to the quality status of the sample test and alert the operator to stop processing if material has not passed the test.

With sufficiently high read rates, the scan errors presented in Table 1 are eliminated as shown in Table 2. Consequently, waste resulting from the errors is eliminated and the process is leaner. Defects and scrap due to lost traceability are reduced. Unnecessary transport resulting from operators bringing batches to wrong process locations is eliminated. Waiting at various process stages for error correction is reduced. There are fewer incorrect production orders due to more accurate WIP inventory data and scan operations are eliminated, reducing unnecessary motion in the process.

\section{Cost and benefits}

The company then compared the benefits derived from the RFID implementation against the costs of implementation. The application was broken down into three different scenarios, each targeting a different set of value drivers. For each scenario the costs and benefits were identified

\begin{tabular}{|l|l|}
\hline \multicolumn{1}{|c|}{ Table 2 - Error } & \multicolumn{1}{|c|}{ RFID solution } \\
\hline $\begin{array}{l}\text { Scanning a bar code representing a production line other } \\
\text { than that the container was filled on }\end{array}$ & Data collection automated \\
\hline Not scanning bar code of container & Data collection automated \\
\hline $\begin{array}{l}\text { Container is put onto a tipping point but the operator } \\
\text { does not perform the goods issue transaction through a } \\
\text { bar code scan }\end{array}$ & Data collection automated \\
\hline $\begin{array}{l}\text { Operator does not check the feedback on the scanner } \\
\text { indicating quality status }\end{array}$ & $\begin{array}{l}\text { Status is automatically checked and operator warned } \\
\text { through alarm trigger }\end{array}$ \\
\hline
\end{tabular}


independently, followed by a cost synergy analysis that identified the associated common costs and benefits when more than one scenario takes place simultaneously. The project team found that synergies play an important role when considering RFID implementations within a manufacturing organisation.

The management was aware of the project, however, financial support management structures at the company changed and the project was ranked lower in priority than before. As a consequence, business case discussions were held at a much later stage, putting the project in jeopardy.

Quantifiable benefits were deduced from error corrections shown on Table 2. Basically, annual wastage due to errors in scanning processes and the resulting traceability loss were taken into account when calculating the annual savings. This was based on an annual statistic which showed how much material has been wasted. Taking an error reduction of $50 \%$ with RFID, we could calculate how much scrappage would be saved. This was a conservative estimate as the number of temporary low-skilled operators in the company, particularly in the peak production season, results in a significantly higher probability of loss of traceability due to bar code scanning errors. To this we added direct labour time savings resulting from the automation of bar code scans. A total of approximately 1000 person hours per annum are required for corrections in the back-end system as a result of errors caused by missed scans.

In the business case analysis, not only the quantifiable benefits associated with RFID implementation were considered but also the impact of soft or unquantifiable benefits were considered. These included improved working procedures, reduced risk of recalls, innovation showcasing and higher visibility of container circulation. These have been found

to be significant and played an important role upon decision making. Another important point that had to be considered was the need for laying out the technical risks and costbenefit sensitivity for any application due to the early stage of the project, such that corrective actions may be taken.

Based on the cost benefit analysis the company calculated a positive return on investment after about two years. Table 3 lists the capital cost components for the solution. The highest costs were allocated to the consultancy service, the web client software for the forklift truck and the MES software.

A key point at this stage was that although data for the business case was collected early in the process by the research team and the management was aware of the project, financial support from management had not been secured in the meantime. After the analysis stage, management structures at the company changed and the project was prioritised lower than before. As a consequence, the business case discussions took place with a new team operating to different organisational criteria which influenced the decisions made about the project and ultimately put the project in jeopardy.

Initially, the project team considered developing a complete solution for a single roll-out. However, management refused to go ahead with full-scale implementation, leading to further discussions and agreement that a phased roll-out would be less risky, in both financial and operational terms, than implementing the full solution at once. A further suggestion was that an implementation could consider various additional applications and be scalable for other processes in the factory - and in other areas of the factory that were not part of the project scope - by reusing the existing infrastructure and data capture for other applications. These discussions helped shape the set up and the business case. Agreeing to a phased roll-out helped the case for financial support for the subsequent stages of the project. 


\begin{tabular}{|c|c|}
\hline Category & Component \\
\hline Software & $\begin{array}{l}\text { Web client software application for truck } \\
\text { MES software application } \\
\text { Web client software application for handheld } \\
\text { MES annual license fee }\end{array}$ \\
\hline Hardware & $\begin{array}{l}\text { Tag Acquisition Processor } \\
\text { Tag Acquisition Processor spare } \\
\text { RFID reader for truck } \\
\text { Truck mounted terminal } \\
\text { Overhead cost for cabling and associated racking, brackets and fixings, barriers and guarding, } \\
\text { installation and commissioning (10\% of total hardware costs) } \\
\text { Set of reader, antenna, terminal and accessories for spare truck } \\
\text { Plastic box for truck terminal } \\
\text { Container tags for } 800 \text { items } \\
\text { RFID handheld terminal } \\
\text { RFID handheld terminal spare } \\
\text { RFID antenna high performance in front of truck } \\
\text { RFID small antenna below truck } \\
\text { Rigid floor tags }\end{array}$ \\
\hline Services & $\begin{array}{l}\text { RFID Consultancy service provided by external company } \\
\text { Project management company (13\% of total hardware costs) } \\
\text { Project management provided by external company } \\
\text { Training provided by external company } \\
\text { Go-live support provided by external company } \\
\text { Documentation service provided by external company } \\
\text { Training company ( } 3.5 \text { person days) }\end{array}$ \\
\hline
\end{tabular}

\section{Selection of project partners}

Given that the implementation of RFID technology in manufacturing was new to the company and therefore there was a lack of knowledge and experience in regards to such an implementation among the employees, the company decided to partner with a research consultancy team and a system integrator. Whereas the researchers took part in the problem analysis, requirements capture and business case analysis, the integration specialist was selected to participate in the design and implementation phase. Later on, management mentioned that this approach immensely contributed to the successful progression of the project.
An important decision within the project was the selection of the middleware vendor for the reader management, data smoothing and filtering, data routing and integration as well as process management and control. In general, companies looking for an RFID middleware solution need to carry out a careful selection as the providers in the market have very different strengths and capabilities. Middleware vendors can be roughly categorised into four groups (Leaver et al. 2004): Pure Players (e.g., OATSystems and Savi Technology) offer RFID device management and RFID data processing software. Application Vendors (e.g., SAP and Manhattan Associates) offer RFID compatible 
applications from warehouse and asset management to more sophisticated solutions with device management, data filtering and aggregation as well as business logic capabilities. Platform giants (e.g., Sun Microsystems and IBM) are providers of strategic RFID middleware architectures, which leverage the vendors' application development, data management and process integration products. Integration Specialists (e.g., TIBCO and Zetes) offer complete solutions and full system integration services based on other companies' products.

Against this background, an integration specialist was selected with expertise in the field of fixed and mobile data capture systems, rugged equipment for harsh environments, forklift and truck-mounted systems, wireless networking as well as backend system integration in various food manufacturing environments. The selection of this vendor was based on the following key evaluation criteria: scalability, integration, flexibility, supported devices, conformance to standards, support services, experience in manufacturing, costs, timescales and general confidence in the solution. These criteria increased over time with more data collection, and ensured a multi-perspective view on the vendors, making confident selection possible.

\section{Project management structure and roles}

The implementation plan was structured in various phases. At the initiation phase, a detailed project plan was created in the project. The proof of concept phase was designed to ensure that the technology is sound and appropriate - taking into account the various environmental factors and constraints imposed on the proposed solution. Experiments were carried out at this stage. For instance tag encapsulation had to comply with hygiene regulations and the set up had to achieve a minimum of $98 \%$ read rates in order for the envisaged benefits to be viable. The forklift installation had to be approved by the forklift lease company. In the pilot phase the solution was expected to be deployed on a single forklift truck and the roll-out phase aimed at the expansion of the system to include the remaining forklift trucks as well as full tagging of all containers and floor locations. In the final closedown phase, the handover of the application was scheduled.

Forming the right team of an RFID project is an important step towards deployment. In this project, different parties were involved, including managers from the company, representatives from the factory, as well as external consultants from universities and a software company for the process analysis and the business case. Additionally, consultants from a system integrator and the provider of the Manufacturing Execution System (MES) in use at the factory participated in the project during the design and implementation phases.

\section{Human factors}

Human factors are a significant but often overlooked part of an RFID implementation process. Our discussion with the company suggested that attention should be given to considerations relating to operator training, health and safety, issues regarding privacy, human-system interaction mechanisms and involvement of the operators in the implementation. Operators needed to be trained on three aspects: RFID technology, RFID-enabled business processes, as well as health and safety associated with operating or handling RFID equipment. Information system administrators and users needed to be trained in the newly implemented infrastructure. When operational managers talked to personnel about the project they realised there might have been a view that RFID was a "replacement technology". Therefore it was important that operators were briefed on why the technology was being deployed and how it would help them in their daily operations.

\section{Discussion}

\section{Practical implications}

As illustrated in the case example, RFID is an enabling technology that manufacturing companies can adopt to enhance asset 
visibility, reduce waste and improve operations. In the course of the project under study, the adopting company learned a number of lessons regarding the management of RFID implementation projects. In this section, we summarise and generalise these lessons to allow for applicability and transfer to similar projects in other organisations.

First, an important success factor for the project was seen in the multi-perspective view on the business problem to be solved in the production system. The company conducted sessions with key personnel in order to analyse operational reliability, technical feasibility, economic viability and organisational compatibility for filtering potential applications and to obtain a rich evaluation of the potential of RFID. In particular, the involvement of key personnel from different organisational units beyond the IT department proved useful to quickly come to a decision on the solution scenario to be investigated in more depth. This strategy of involving a heterogeneous group of people also helped the company to increase awareness and acceptance of the project.

Second, during the requirements analysis phase, the company found that visualisation techniques can help in analysing complex processes and evaluating the potential application of RFID to these processes. Against the background that some members of the project team were not familiar with the details of manufacturing operations, visual depictions of the process showed to improve communications among the different parties involved in the project. In this context, it also proved crucial to stay in close contact with the local personnel throughout the project because additional questions relating to the existing manufacturing system continuously arose.

Third, a lesson learned from the business case analysis phase was that companies should not evaluate isolated applications, which would in most cases suffer from substantial technology costs, but rather consider synergies among different applications, potential risks and qualitative benefits to gain a clear business rationale. As a consequence, the company was able to pursue an infrastructure-oriented strategy by implementing small-scale applications and extending them in the future to other projects thereby exploiting the new RFID infrastructure and data capturing capabilities to minimise risk and complexity. However, it also became clear that this long-term approach could only be realised with full support by the organisation's top management. In the studied case, the temporary lack of top management support led to a longer delay between concept development and implementation. Therefore, an additional lesson was that project teams should secure support and formal commitment of key management and budget holders at an early stage to speed up deployment.

Fourth, the case also pointed to the importance of external knowledge on RFID implementations. Forming the right team of an RFID project is an important step towards deployment. However, even IT-intensive organisations that have gathered experiences with bar code solutions usually do not possess the technological know-how to design and implement RFID systems on their own. It is therefore necessary to leverage available expertise not only from within but also from outside the company to avoid problems caused by inexperience and to obtain an independent view by experts. The vendor selection should be based on several criteria such as scalability, flexibility, supported devices, conformance to standards, support services, experience of manufacturing environments, costs, timescales and general confidence to gain a comprehensive picture of the offered products and services. In the studied case example, being supported by a provider of systems integration services proved particularly helpful in the evaluation of different alternative architectural approaches, e.g., regarding the comparison of a mobile versus a fixed reader solution. 
Not least, the company set the focus of the project not only on technological change but also on preparing their staff for the change of business processes and work practices. Among others, comprehensive training material for workers, managers and administrators was developed and all personnel whose work would be affected by the RFID implementation were briefed in advance to reduce their concerns. We suggest practitioners to do the same as avoiding human factors might seriously jeopardise the project. Moving from manual based information push mechanisms to an automated pull mechanism can bring on the much debated surveillance feeling in the work space. Facilitation and encouragement of interactive contributions from operators are aspects that might make the system more acceptable to the users (Nam and Konomi, 2005). Finally, during RFID adoption, health and safety guidelines need to be reviewed and complied.

\section{Theoretical implications}

Besides the practical perspective, the case also offers some theoretical insights into the interplay between RFID technology and its use in the organisational context. The manufacturing domain that we considered in this study differs in various ways from applications in the retail supply chain, which most other RFID-related works focus on. As a consequence, an interpretation of the case against the background of different theoretical frameworks can complement our current understanding of RFID.

On the one hand, the case can be seen as a detailed example of a technology adoption process within an organisation. The majority of existing IT adoption studies follows a "factor approach" (Kurnia \& Johnston, 2000; Jeyaraj et al., 2006; Williams et al., 2009), which assumes that a number of predicting variables identified at a particular time determine adoption decisions of an organisation. The paradigm underlying these works usually traces back to Rogers' "Diffusion of Innovations" (DOI) theory (Rogers, 2003), which posits that adoption is determined by five perceived attributes of an innovation: relative advantage, compatibility, complexity, trialability and observability. Regarding the studied confectionery manufacturer, it is evident that relative advantage compared to the existing bar code solution was one of the main drivers of the project. In this specific case, the superiority of RFID included a number of quantifiable (e.g. time, error and waste reduction) as well as qualitative process improvements. A second influencing factor can be seen in the role of compatibility due to the necessity to integrate any new solution to the company's existing ERP and MES systems. Moreover, the organisation's dependence on an external systems integration service provider highlights the role of the perceived technological complexity, which could only be reduced by the acquisition of knowledge from the outside of the company.

While DOI theory concentrates on the characteristics of an innovation as the driving forces of its adoption, other researchers have proposed to complement these by contextual factors known from organisational or institutional theory (Yang and Jarvenpaa, 2005). Tornatzky and Fleischer (1990) distinguish between three elements of the technological innovation decision: (i) the technological context, which describes existing technologies in use and technical skills in the organisation; (ii) the organisational context, which refers to internal measures such as its size or support by top management; and (iii) the environmental context, in which the organisation is embedded (i.e., business partners, competitors, industry, society). While the technological context of our case study is already covered by the logic of DOI theory as discussed above, we also found evidence for the influence of organisational factors in the considered case. First of all, the standing of the project fell and rose with the support by the company's top management. Notwithstanding the clear business case, the lack of sponsors among company executives resulted in a significant delay between design and implementation. Second, we interpret the 
relative importance of proactive change management in the course of the project as a sign for the potential negative impact of internal resistance against technological change. In contrast to these organisational factors, we did not find any evidence for the significance of environmental factors, which seems little surprising given the fact that container management is a typical closedloop scenario within the limits of the organisation.

On the other hand, the case presented a specific application of RFID in production systems and the business value that the technology creates in this context. IT value research in general poses a classical research stream that aims at understanding the impact of IT investments on performance measures on an economical level down to the level of individual workflows. In our case, we investigated how RFID technology helps a company achieve efficiency gains in its production system by improving container management practices. Baars et al. (2009) as well as Thiesse et al. (2009), following a concept developed by Mooney et al. (1996), propose to classify the impact of RFID on business processes into three groups: automational, informational and transformational effects. The benefits generated by automation are mainly the result of the substitution of manual labour. For operational processes, this means time and personnel cost savings, whereas in terms of administrative processes, the IT benefits manifest themselves through the simplification of the monitoring and reporting activities. In contrast, the value of computerisation arises from the ability of RFID not only to gather data more efficiently but also to improve the respective level of detail and timeliness, which may lead to greater flexibility and better decision-making in the management of supply chains. Transformational effects, again, lead to an increase in value resulting from the technology and a simultaneous change in the business process, e.g. in the form of novel scheduling heuristics made possible by precise real-time information on the status and the location of production lots.

Regarding the case of container management, we found three impacts on operational and management processes. First, automational effects could be observed through the elimination of manual scanning activities. RFID allows the manufacturer to automatically track IBC's and their contents along the production line without having to capture the data by staff members, which results in lower cost per data set captured and lower error rates. Furthermore, the same data allow operators to easily locate containers in the system, which represents an example of process computerisation. Again, the process in itself is not structurally changed by the new technology, but here the created value does not stem from automation alone. Third, more efficient management of containers also allows the company to reduce the total number of these physical assets on the long run, which can be interpreted as an informational effect on the level of management processes. In contrast to that, the case does not provide an example of process transformation, neither regarding operational nor management processes.

\section{Summary and conclusions}

The aim of this paper was to improve the understanding of RFID applications in the manufacturing domain by investigating one specific RFID project for a confectionery manufacturer in detail. In this project, RFID and its potential to effectively support the tracking of reusable containers within the four walls of a factory was examined. Through interviews with company management we presented our observations and findings from the project and discussed success contributors to project planning. The detailed study of the case and the resulting implications can support project managers and system designers planning to implement an RFID application in manufacturing. From a more theoretical perspective, this paper contributes to the existing gap in the literature on empirical studies in the field of RFID in manufacturing. 
As with any case study, this research is not without its limitations and it is hence important to critically evaluate the results. Some of these limitations can be seen as positive directions for future research under the same theme. Firstly, in contrast to quantitative methodologies based on large samples, the potential inability to generalise from the findings can limit the use of case study methods. Therefore, the validity of the research would benefit from insights obtained from additional cases or survey data. Secondly, the study is limited by the fact that the system under consideration was not yet in productive use. It is therefore not possible to make solid statements on the long-term benefits that could be drawn from RFID in

\section{References}

Angeles, R. (2005). "RFID Technologies: Applications and Implementation Issues," Information Systems Management, 22 (1), pp. 51-65.

Baars, H., Gille, D. Strüker, J. (2009). "Evaluation of RFID Applications for Logistics: A Framework for Identifying, Forecasting and Assessing Benefits," European Journal of Information Systems, 18 (6), pp. 578-59.

Bapat, V., Tinnell, K. (2004). "RFID in Manufacturing: A Practical Guide on extracting measurable Value from RFID Implementations in Plant and Warehousing Operations," Rockwell Automation, retrieved from: http://www.rockwellautomation.com.

BearingPoint, (2005). "Beyond Compliance: the Future Promise of RFID," BearingPoint, retrieved from: http://www.rfidjournal.com/whitepape rs/download/39.

Benbasat, I., Goldstein, D.K., and Mead, M. (1987). "The case research strategy in studies of information systems," MIS Quarterly, 11(3), 369-387.

Bose, I., Pal, R. (2005). "Auto-ID: Managing Anything, Anywhere, Anytime in the
WIP tracking as well as additional technological or organisational issues that arise over time. Finally, based on these findings, an integrated framework could be developed that supports system designers during an RFID project from the problem analysis to the actual deployment and maintenance.

\section{Acknowledgement}

This work is partly funded by the by the European Commission within the Sixth Framework Programme (2002-2006) project BRIDGE (Building Radiofrequency IDentification solutions for the Global Environment), IP Nr. IST-FP6-033546.

Supply Chain," Communications of the ACM, 48(8), 100-106.

Collins, J. (2006). "DaimlerChrysler Putting RFID Tags in Kanban Cards," RFID Journal, retrieved from: http://www.rfidjournal.com/article/vie w/2405

Dutta, A., Lee, H.L., Whang, S. (2007). "RFID and Operations Management: Technology, Value, and Incentives," Production and Operations Management, 16(5), 646655.

Dyer, W.G. and Wilkins, A.L. (1991). "Better Stories, not better Constructs, to generate better Theory," Academy of Management Review, 16(3), 613-619.

Eisenhardt, K.M. (1989). "Building Theories from Case Study Research," Academy of Management Review, 14(4), 532-550.

Gaukler, G., Hausman, W. (2008). "RFID in mixed-model automotive assembly operations: Process and quality cost savings," IIE Transactions, 40(11), 1083-1096.

Gaukler, G.M., Seifert, R.W. (2007). "Applications of RFID in Supply Chains," In: Jung, H., Chen, F.F., 
Bongju, J. (eds) Trends in Supply Chain Design and Management: Technologies and Methodologies. Springer, Heidelberg, Germany, pp. 29-48.

Gunasekaran, A., Ngai, E.W.T. (2007). "Managing digital enterprise," International Journal of Business Information Systems, 2(3), 266-275.

Günther, O., Kletti, W., Kubach, U. (2008). RFID in Manufacturing. Berlin: Springer.

Heese, H.S. (2007). "Inventory Record Inaccuracy, Double Marginalization, and RFID Adoption," Production and Operations Management, 16(5), 542553.

Hozak, K., Collier, D.A. (2008). "RFID as an Enabler of Improved Manufacturing Performance," Decision Sciences, 39(4), 859-881.

Jeyaraj, A., Rottman, J.W., Lacity, M.C. (2006). "A review of the predictors, linkages, and biases in IT innovation adoption research," Journal of Information Technology, 21(1), 1-23.

Jones, P., Clarke-Hill, C., Shears, P., Comfort, D., Hillier, D. (2004). "Radio frequency identification in the UK: opportunities and challenges," International Journal of Retail \& Distribution Management, 32(3), 164171.

Jun, H.-B., Kiritsis, D., Xirouchakis, P. (2007). "Research issues on closedloop PLM." Computers in Industry, 58(8-9), 855-868.

Kang, Y., Gershwin, S. (2005). "Information inaccuracy in inventory systems: stock loss and stockout," IIE Transactions, 37(9), 843-859.

Kärkkäinen, M., Holmström, J. (2002). "Wireless product identification: enabler for handling efficiency, customisation and information sharing," Supply Chain Management:
An International Journal, 7(4), 242252.

Kurnia, S., Johnston, R.B. (2000). "The need for a processual view of interorganizational systems adoption," Journal of Strategic Information Systems, 9(4), 295-319.

Leaver, S.C., Mendelsohn, T., Overby, C.S., Yuen, E.H. (2004). "Evaluating RFID Middleware,"

Forrester. Researchretrieved from: http://www.forrester.com/Research/D ocument/Excerpt/0,7211,34390,00.ht $\underline{\mathrm{ml}}$.

Lee, H., Özer, Ö., (2007). "Unlocking the Value of RFID," Production and Operations Management, 16(1), 4064.

Lindau, R., Lumsden, K. (1999). "The use of automatic data capture systems in inventory management." International Journal of Production Economics, 59(1-3), 159-167.

McBeath, B. (2006). "RFID for Manufacturers," ChainLink Research, retrieved from: www.chainlinkresearch.com.

McFarlane, D. (2009). "Roadmapping for RFID," Distributed Information and Automation Lab Working Paper, University of Cambridge.

McFarlane, D., Sheffi, Y. (2003). "The Impact of Automatic Identification on Supply Chain Operations," International Journal of Logistics Management, 14(1), 1-18.

Meredith, J. (1998). "Building Operations Management Theory through Case and Field Re-search," Journal of Operations Management, 16(4), 441454.

Mooney, J.G., Gurbaxani, V., Kraemer, K. (1996). "A Process Oriented Framework for Assessing the Business Value of Information Technology," The DATA BASE for 
Advances in Information Systems, 27(2), 68-81.

Nam, C.S., Konomi, S. (2005). "Usability Evaluation of Query Lens: Implications for context-aware Information Sharing using RFID," International Conference of HumanComputer Interaction, Calgary.

Ngai, E.W.T., Moon, K.L.K., Riggins, F.J.,Candace, Y.Y. (2008). "RFID Research: An Academic Literature Review (1995 - 2005) and Future Research Directions," International Journal of Production Economics, 112(2), 510-520.

O'Connor, M.C. (2006a). "Clothing Maker Says RFID Significantly Improves Production," RFID Journal, retrieved from:

http://www.rfidjournal.com/article/artic leview/2605/2/1/

O'Connor, M.C. (2006b). "Blommer Tracking Chocolate with RFID," RFID Journal, retrieved from: http://www.rfidjournal.com/article/artic leview/2402

Ohno T. (1998). Toyota Production System: Beyond Large-Scale Production. Florence: Productivity Press.

Paré, G. (2004). "Investigating information systems with positivist case study research," Communications of the AIS, 13, 233-264.

Patton, M.Q. (2002). Qualitative Evaluation and Research Methods. Newburk Park: Sage Publications.

Rekik, Y., Sahin, E., Dallery, Y. (2008). "Analysis of the impact of the RFID technology on reducing product misplacement errors at retail stores." International Journal of Production Economics, 112(1), 264-278.

Rekik, Y., Sahin, E., Dallery, Y. (2009). "Inventory inaccuracy in retail stores due to theft: An analysis of the benefits of RFID," International
Journal of Production Economics, 118(1), 189-198.

Rogers, Everett M. (2003). Diffusion of Innovation. New York: Free Press.

Srivastava, B. (2004). "Radio frequency ID technology: The next revolution in SCM." Business Horizons, 47(6), 6068.

Strohbach, M., Gellersen, H.W., Kortuem, G., Kray. C. (2004). "Operative artefacts: assessing real world situations with embedded technology." In: Davies, N., Mynatt, E., Siio, I. (eds), UbiComp 2004: Ubiquitous Computing, 11-14 September 2005 Tokyo, Heidelberg: Springer, pp. 250-267.

Thiesse, F., Al-Kassab, J., Fleisch, E. (2009). "Understanding the value of integrated RFID systems: a case study from apparel retail." European Journal of Information Systems, 18(6), 592-614.

Thiesse, F., Dierkes, M., Fleisch, E. (2005). "LotTrack: RFID-based Process Control in the Semiconductor Industry," IEEE Pervasive Computing, 5(1), 47-53.

Thiesse, F., Fleisch, E. (2008). "On the Value of Location Information to Lot Scheduling in complex Manufacturing Processes." International Journal of Production Economics, 112(2), 532547.

Tornatzky, L.G. and Fleischer, M. (1990). The processes of technological innovation, Lexington. Lexington Books.

Wessel, R., (2006). Clothing Manufacturer Invests Its ROI in RFID, retrieved from: $\quad$ http://www.rf-itsolutions.com/uploads/tx easydownl oadlist/200608 gardeur.pdf

Williams, M.D., Dwivedi, Y.K., Lal, B., Schwarz, A. (2009). "Contemporary trends and issues in IT adoption and 
Kürschner et al.: Implementing RFID in Production Systems: A Case Study from a Conf

Implementing RFID in Production Systems: A case Study from a Confectionery Manufacturer/ Kürschner et al

diffusion research," Journal of Information Technology, 24(1), 1-10.

Yang, G. and Jarvenpaa, S. (2005). "Trust and radio frequency identification (RFID) adoption with in an alliance." 38th Annual Hawaii International
Conference on System Sciences, Big Island.

Yin, R.K., (2003). Case Study Research: Design and Methods. Thousand Oaks: Sage Publication. 


\section{About the Authors}

Chris Kürschner holds a diploma degree in business administration from the University of Wuerzburg and a doctoral degree in business administration from the University of St. Gallen. After his time at SAP Research and the Institute of Technology Management at the University of St. Gallen, he decided to continue working with SAP. $\mathrm{He}$ is now a business process consultant in the area of production planning and scheduling as well as project systems.

\section{Alexandra Brintrup}

Dr. Alexandra Brintrup is a senior research fellow in the CABDyN Complexity Centre at Oxford University. After reading Manufacturing Systems Engineering, Dr. Brintrup completed her MSc and PhD degrees in Computer Science at Cranfield University. She then worked as a research associate at the Distributed Information and Automation Laboratory, University of Cambridge. Her research interests lie in the design of computational intelligence for operations research problems. Some of her most published work includes the use of interactive multi-objective genetic algorithms in optimisation, multi-agent based supply network analysis and management, and the development of smart embedded systems for lean manufacturing and product lifecycle management.

At present she is carrying out research the robustness of complex adaptive systems, and decision making in dynamic networks

Paul Bowman Paul Bowman holds an MSc in Telecommunications Engineering from University College London and works for BT in the UK. His recent research interests have been focused on low-powered sensor networks and their applications including: third generation telecare monitoring systems, smart metering and active RFID in supply chains. His previous background has covered acoustics and telephonometrics at the ITU (Geneva), video quality assessment and radio systems engineering. $\mathrm{He}$ is currently an operational support systems solution designer.

Erica Dubach is a $\mathrm{PhD}$ candidate at the Swiss Federal Institute of Technology Zürich (ETH Zürich) since February 2007, and a senior researcher in the Auto-ID Lab University of St. Gallen / ETH Zürich since February 2009. She holds a Master of Science in Software Engineering and has taught at the University of Applied Sciences $(\mathrm{HTI})$ in Berne. She has worked in innovation and research at Northwestern University (Chicago), UBS, Swissair, IBM and most recently at SAP Research in Zürich. Her research focus is pervasive and mobile computing and their business applications in the retail industry, especially consumer applications on mobile phones and public displays.

Frédéric Thiesse is full professor of Information Systems Engineering at the University of Wuerzburg, Germany. He holds a diploma degree in management information systems from the University of Mannheim as well as a doctoral degree with highest distinction and a "habilitation" (postdoctoral qualification) in business administration from the University of St. Gallen. The results of his research were published, among others, in the European Journal of Information Systems, the Journal of Strategic Information Systems, the International Journal of Production Economics, Electronic Markets, and IEEE Internet Computing. His research interests include the impact of novel information and communication technologies on business processes, supply chain management, IS adoption and acceptance, and the design of mobile and ubiquitous systems. 